\title{
Comparative study of I+PRN ranibizumab versus bevacizumab in the clinical setting
}

This article was published in the following Dove Press journal:

Clinical Ophthalmology

18 July 2012

Number of times this article has been viewed

\author{
Angela M Carneiro ${ }^{1,2}$ \\ Luis S Mendonça' \\ Manuel S Falcão ${ }^{1,2}$ \\ Sofia L Fonseca' \\ Elisete M Brandão' \\ Fernando M Falcão-Reis ${ }^{1,2}$ \\ 'Department of Ophthalmology of \\ Hospital de São João, Porto, Portugal; \\ ${ }^{2}$ Faculty of Medicine of University of \\ Porto, Porto, Portugal
}

Purpose: We compared the efficacy of intravitreal ranibizumab and bevacizumab for treating neovascular age-related macular degeneration using an on-demand regimen.

Methods: A total of 186 wet age-related macular degeneration eyes of 186 treatment-naïve patients were compared retrospectively (67 eyes treated with ranibizumab with 91 treated with bevacizumab). At baseline, mean age, best corrected visual acuity, and angiographic lesion types were similar in both groups. Best corrected visual acuity and ocular coherence tomography were evaluated.

Results: Sixty eyes treated with ranibizumab and 85 eyes treated with bevacizumab completed a 12-month evaluation. At 12 months, mean best corrected visual acuity increased by +6.65 letters with ranibizumab treatment and by +5.59 with bevacizumab treatment $(P=0.64)$. Visual acuity improved by $\geq 15$ letters in 15 eyes treated with ranibizumab and in 21 eyes treated with bevacizumab $(P=0.75)$. An overall reduction in ocular coherence tomography central thickness occurred for all time points. The mean number of injections per eye was 5.97 with ranibizumab and 5.92 with bevacizumab $(P=0.90)$.

Conclusion: Intravitreal therapies with ranibizumab or bevacizumab have similar visual and anatomical results. These results confirm those of comparison of Age-Related Macular Degeneration Treatment Trials in as-needed cohorts in clinical practice. Randomized long-term clinical trials are necessary to examine the systemic safety of these treatments.

Keywords: AMD, anti-VEGF therapy, bevacizumab, choroidal neovascularization, ranibizumab, wet AMD

\section{Introduction}

Choroidal neovascularization (CNV) secondary to age-related macular degeneration (AMD) is the leading cause of severe central vision loss in individuals over the age of 65 years in Europe, North America, and Australia. ${ }^{1-7}$ Intravitreal anti-vascular endothelial growth factor (VEGF) therapy with ranibizumab (Lucentis ${ }^{\circledR}$, Novartis Pharma AG, Basel, Switzerland and Genentech, South San Francisco, California) and bevacizumab (Avastin ${ }^{\circledR}$, Genentech, South San Francisco, California) has revolutionized the management of this disease, as these were the first forms of treatment that significantly improved visual acuity in patients with neovascular AMD. ${ }^{8-13}$

Bevacizumab is a full-length, recombinant, humanized, monoclonal antibody with a molecular weight of $148 \mathrm{kD}$, while ranibizumab is a recombinant, humanized, monoclonal Fab fragment of $49 \mathrm{kD} .{ }^{14}$ In primate and rabbit studies, a humanized antibody with a framework similar to that of bevacizumab was compared with the Fab version of bevacizumab. Under the tested conditions, Fab showed greater diffusion 
than the $\mathrm{IgG}$; IgG progression stopped either at the outer plexiform or at the internal limiting membrane and did not reach the subretinal space at the same concentration as the Fab fragment. ${ }^{14,15}$ Thus, ranibizumab was developed as a more effective treatment for CNV. A large number of multicenter controlled clinical trials reported unprecedented visual results for treating wet AMD with ranibizumab. ${ }^{10,12,16-18}$ Subsequently, ranibizumab was approved by the US Food and Drug Administration and the European Medicines Agency for the treatment of neovascular AMD.

The best visual results were obtained with fixed monthly injections such as in the Anti-VEGF Antibody for the Treatment of Predominantly Classic Choroidal Neovascularization in AMD (ANCHOR) and Minimally Classic/Occult Trial of the Anti-VEGF Antibody Ranibizumab in the Treatment of Neovascular AMD (MARINA) trials. ${ }^{10,12,16,17,19}$ Attempts to space treatment periods such as in the $\mathrm{PIER}^{20}$ and SAILOR ${ }^{21}$ trials, with three initial monthly injections followed by a quarterly regimen, resulted in worse visual results at 52 weeks. In the MARINA, ANCHOR, and PIER trials, the greatest visual improvement occurred with the first three injections. This led to Novartis recommending that patients should be treated with an initial 3-injection-loading dose of Lucentis ${ }^{\circledR} .{ }^{22}$ In clinical practice, after the loading dose, many ophthalmologists use injections "as-needed" or using a pro re nata (PRN) treatment strategy based on clinical and ocular coherence tomography (OCT) data. ${ }^{23-25}$

Bevacizumab is a VEGF inhibitor that neutralizes all known biologically active isoforms of VEGF-A. The Food and Drug Administration approved its use in 2004 for the intravenous treatment of metastasized colon adenocarcinoma. ${ }^{26,27}$ After the first intravitreal use of bevacizumab reported in $2005,{ }^{9}$ its off-label use for treating wet AMD was widely adopted. The apparent safety and efficacy of intravitreal use of this full-length antibody has been reported following numerous retrospective series and small prospective clinical studies. ${ }^{8,11,28,29}$ Visual improvement can occur immediately after the first injection and many ophthalmologists use bevacizumab in clinical practice using a $1+$ PRN treatment..$^{30,31}$

The results of several large randomized, double-blind clinical trials comparing the effectiveness of both drugs for treating wet AMD are not yet available (VIBERA NCT00559715, IVAN CTEU Bristol, MANTA NCT00710229, LUCAS NCT01127360, and GEFAL NCT01170767 trials). The recent publication of Age-Related Macular Degeneration Treatment Trials (CATT) results, a prospective, randomized, comparative effectiveness study of bevacizumab and ranibizumab in fixed monthly or as-needed regime of treatment, demonstrated similar efficacy results between the two molecules. However, the bevacizumab as-needed cohort showed inconclusive results when compared to ranibizumab monthly or bevacizumab monthly. Additionally, OCT results were better in ranibizumab-treated patients. ${ }^{13}$

To date, a limited number of other studies have directly compared the two drugs using the same treatment and retreatment protocols for both drugs. ${ }^{32-35}$ With some limitations, these studies suggest similar visual outcomes of treatment with the two drugs.

To our knowledge, apart from the CATT, no other published reports have compared both drugs using an $1+\mathrm{PRN}$ strategy of treatment to evaluate efficacy parameters at 1,2 , $3,4,5,6,9$, and 12 months.

In this single-center retrospective analysis we compared the efficacy of bevacizumab and ranibizumab at 12 months using an as-needed or 1+PRN strategy of treatment in a clinical practice setting.

\section{Methods}

We conducted a retrospective, observational, uncontrolled, non-randomized and unicentric analysis to compare the efficacy of intravitreal treatments with ranibizumab and bevacizumab for wet AMD. A review of clinical charts of selected patients was performed.

Approval from the Ethics Committee of Hospital São João was obtained for intra-vitreal "off-label" use of bevacizumab in wet AMD in December 2006. Each patient signed a written informed consent. The study was carried out in accordance with the Declaration of Helsinki.

In our department, before ranibizumab availability, patients with wet AMD were treated with intravitreal bevacizumab (1.25 mg). When INFARMED (the Portuguese health authority) approved the use of ranibizumab in Portugal in July 2008, ranibizumab was used ( $0.5 \mathrm{mg}$ ) in our department for treating naïve patients. Therefore, drug choice was not based on medical or social characteristics of the patient, but based solely on enrollment date. Patients enrolled from December 2006 through July 2008 were treated with bevacizumab; patients enrolled after July 2008 were treated with ranibizumab. Therefore, no drug choice was offered to the patient or the ophthalmologist. No patient refused the assigned treatment.

Inclusion and exclusion criteria are summarized in Table 1.

In patients who presented with wet AMD in both eyes, only the right eye was included in the study. Exclusion criteria 
Table I Inclusion and exclusion criteria

\section{Inclusion criteria}

Age-related macular degeneration

Subfoveal CNV

$B C V A \geq 20 / 1000$

Patients must be age 50 years or older

Patients must sign a written informed consent form

In cases of bilateral disease, only the right eye was included

Exclusion criteria

Previous treatment for wet AMD, including laser, radiation, PDT, or any anti-VEGF therapy

Patients who present with CNV due to other causes than AMD, including pathological myopia, ocular histoplasmosis syndrome, angioid streaks, multifocal choroiditis, choroidal rupture

Patients with any retinal vasculopathies, including diabetic retinopathy, retinal vein occlusions, etc, in the study eye

Patients with previous subfoveal or juxtafoveal laser treatment Patients with concomitant diseases in the study eye such as uveitis, retinal pigment epithelium rips, central serous corioretinopathy, acute ocular or peri-ocular infection Patients with advanced glaucoma or intraocular pressure in the study eye $>22 \mathrm{mmHg}$ in spite of adequate treatment or medication Premenopausal women not using adequate contraception

Abbreviations: AMD, age-related macular degeneration; CNV, choroidal neovascularization; PDT, photodynamic therapy; VEGF, vascular endothelial growth factor; $\mathrm{BCVA}$, best-corrected visual acuity.

included previous treatments for wet AMD, such as laser, photodynamic therapy, or intravitreal anti-VEGF therapy, before arrival at our center.

We included in this analysis the first 67 patients treated with ranibizumab and the first 91 patients treated with bevacizumab.

At the first visit, best-corrected visual acuity (BCVA) using Early Treatment Diabetic Retinopathy Study (ETDRS) charts, stereoscopic fundus evaluation, fluorescein angiography (FA), and optical coherence tomography (OCT) with Stratus OCT, version 4.0.2 (Carl Zeiss Meditec, Dublin, CA, USA) were performed. OCT imaging consisted of 6 diagonal fast, low-density 6-mm scans and high density 6-mm scans with vertical and horizontal lines through the lesion. Foveal thickness was determined manually using callipers in the high-density vertical and horizontal lines.

CNV lesions were classified angiographically into predominantly classic, minimally classic, occult with no classic, or retinal angiomatous proliferations. All angiographic lesion subtypes, even those with areas of fibrosis, geographic atrophy, hemorrhage, or retinal pigment epithelium detachments greater than $50 \%$ of the size of the lesion were included in the study. Fibrotic scars without active CNV were not included in the study. ETDRS score was not an exclusion criterion. All patients with BCVA between 20/1000 and 20/20 were treated. In patients with very low ETDRS scores, intravitreal therapy was offered if further loss of visual function was recognized as detrimental to their quality of life. These patients included patients with subfoveal hemorrhages. Patients with visual acuity greater than 20/40 were treated when OCT and FA showed active CNV.

The existence of CNV was determined based on FA and OCT by two researchers (AMC and EMB).

Intravitreal via pars plana injection was performed if active CNV was identified on FA or if any intraretinal or subretinal fluid was present on OCT scans. Patients with a medical history of myocardial infarction or previous stroke were typically not treated, but the final decision was made with the patient based on a clinical risk/benefit evaluation for each case. Injection was performed in an operating room setting after a 3-day cycle of topical prophylactic ofloxacin. Cutaneous and conjunctival disinfection with iodopovidone was performed $5 \mathrm{~min}$ and immediately before the procedure. Ofloxacin was used topically during the 4 days following the procedure. Follow-up visits occurred in the normal clinical settings of our center, typically $28 \pm 7$ days after treatment. All patients were re-evaluated using ETDRS scores, fundoscopic examination, and OCT. The following re-treatment criteria were used: new macular hemorrhage or presence of subretinal or intra-retinal fluid on OCT or leakage on FA. No patient received combination therapy with photodynamic therapy, intravitreal triamcinolone, or any other anti-VEGF therapy. Re-injection was performed 5-7 days after the medical visit, depending on operating room availability.

Visual results were compared at baseline and at each re-evaluation.

The primary outcomes measured included variation in mean BCVA and in mean OCT foveal thickness between baseline and at 1, 2, 3, 4, 5, 6, 9, and 12 months.

Patients that suspended intravitreal treatment for nonophthalmic reasons before completing the 12-month period were not included in efficacy analysis.

Moderate visual loss was considered when an ETDRS loss equal or superior to 15 letters occurred. Significant visual gain was considered when there was an ETDRS improvement of at least 15 letters. Mean BCVA ETDRS score variations were compared in both groups after each visit.

Statistical analysis was made using SPSS 16.0 (SPSS Inc, Chicago, IL, USA). Two-tailed $t$-tests were used to compare mean changes in BCVA and central retinal thicknesses on OCT. Chi-squared tests were used to compare non continuous variables. A $P$ value of $<0.05$ was considered statistically significant. Values in the text are represented as the mean (standard deviation [SD]). 


\section{Results}

Sixty-seven eyes of 67 patients were included in the ranibizumab cohort and 91 eyes of 91 patients were included in the bevacizumab-treated group. Visual acuity was similar between the groups at baseline. Both groups were similarly distributed in age and gender: 77.1 years and $41.8 \%$ males in the ranibizumab group and 76.5 years and $40.7 \%$ males in the bevacizumab group; $P=0.62$ and $P=0.997$, respectively (Table 2). Angiographic lesion subtypes were also similar (Table 2).

Mean BCVA at baseline was 20/160 (41.5 ETDRS score) in the ranibizumab group and 20/160 (40.6 letters) in the bevacizumab group $(P=0.72)$.

Sixty patients treated with ranibizumab (90\%) and 85 patients treated with bevacizumab (93\%) completed 12 months of follow-up. Thirteen patients (6 in the bevacizumab group and 7 in the ranibizumab group) were lost during follow-up. Two patients from the bevacizumab group sustained a stroke and were not able to complete the 12 months of follow-up. There was no statistically significant difference in the number of patients lost to follow-up. All patients were included in statistical analysis until they were lost during follow-up.

In both groups, a significant increase was observed in visual acuity after 12 months of treatment. In the ranibizumab group $(n=60)$, vision improved to $20 / 125$ (48.8 letters), with a mean gain of +6.65 letters $(P<0.001)$. In the 85 patients treated with bevacizumab, vision improved to 20/125 (47.6 letters), with a mean gain of $+5.59(P<0.001)$. However, there was no statistical difference between the two groups $(P=0.64)$. Patients that did not complete 12 months of follow-up in both groups also experienced an overall gain of visual acuity at the date of the last visit: +3.5 letters in the

Table 2 Baseline characteristics of the patients

\begin{tabular}{|c|c|c|c|}
\hline & $\begin{array}{l}\text { Ranibizumab } \\
(n=67)\end{array}$ & $\begin{array}{l}\text { Bevacizumab } \\
(n=91)\end{array}$ & $\boldsymbol{P}$ \\
\hline Age - mean $( \pm S D)$ & $77.1( \pm 7.1)$ & $76.5( \pm 8.0)$ & $0.61^{a}$ \\
\hline Males - n (\%) & $28(41.8 \%)$ & 37 (40.7\%) & $0.997^{b}$ \\
\hline \multicolumn{4}{|l|}{ Initial BCVA } \\
\hline mean $( \pm S D)$ & $41.5( \pm 22.8)$ & $40.6( \pm 20.5)$ & $0.72^{\mathrm{a}}$ \\
\hline \multicolumn{4}{|l|}{ Initial foveal thickness } \\
\hline mean $( \pm S D)$ & $318.3( \pm 136.9)$ & $287.0( \pm 147.9)$ & $0.19^{a}$ \\
\hline \multicolumn{4}{|c|}{ Angiographic lesion subtype } \\
\hline Predominantly classic & 17 & 12 & \\
\hline Minimally classic & 18 & 31 & $0.22^{\mathrm{b}}$ \\
\hline Occult with no classic & 24 & 39 & \\
\hline RAP & 8 & 9 & \\
\hline
\end{tabular}

Notes: ${ }^{a}$ Pearson chi-square; bindependent sample $t$-test.

Abbreviations: BCVA, best corrected visual acuity in ETDRS scores; SD, standard deviation; RAP, retinal angiomatous proliferation. bevacizumab group (initial mean BCVA 20.5 letters; mean follow-up of 108 days) and +6.4 letters in the ranibizumab group (initial mean BCVA 35.6 letters; mean follow-up time of 131 days).

Details regarding progression of variation of mean BCVA can be observed in Figure 1.

In the ranibizumab group, vision increased by 4.7 letters $(\mathrm{n}=67,100 \% ; P<0.001)$ after the first treatment. In the bevacizumab group, the first injection yielded a visual improvement of 4.0 letters ( $\mathrm{n}=91,100 \% ; P=0.001)$.

Analysis of overall patient results at the end of the 12 months showed that $6.9 \%$ of patients had a moderate visual loss, including three ranibizumab-treated eyes $(5.0 \%)$ and seven bevacizumab-treated eyes (8.2\%). Visual gain occurred in $70.0 \%(n=42)$ of eyes treated with ranibizumab and $65.9 \%$ $(\mathrm{n}=56)$ of eyes treated with bevacizumab) $(P=0.60)$. Significant visual gain, defined as an increase of at least 15 ETDRS letters, occurred in $24.8 \%$ of eyes ( 15 eyes treated with ranibizumab, $25.0 \%$ and 21 eyes treated with bevacizumab, $24.7 \%$ ). These differences between the groups were not statistically significant ( $P=0.45$ and $P=0.97$, respectively).

Mean initial foveal thickness on OCT between the groups was statistically similar $(318.3 \mu \mathrm{m}$ in the ranibizumab group and $287.6 \mu \mathrm{m}$ in the bevacizumab group; $P=0.19$ ) (Table 2). There was a noticeable decrease in foveal thickness 1 month after the first treatment (ranibizumab: $-103.9 \mu \mathrm{m}$, $P<0.001$ vs baseline; bevacizumab: $-79.5 \mu \mathrm{m}, P<0.001$ vs baseline) that was not statistically different between treatment groups $(P=0.287)$. This improvement was sustained throughout follow-up (Figure 2); at 12 months, mean foveal thickness was reduced by $115.15 \mu \mathrm{m}(P<0.001$ vs baseline) in the ranibizumab group $(\mathrm{n}=84)$, and by

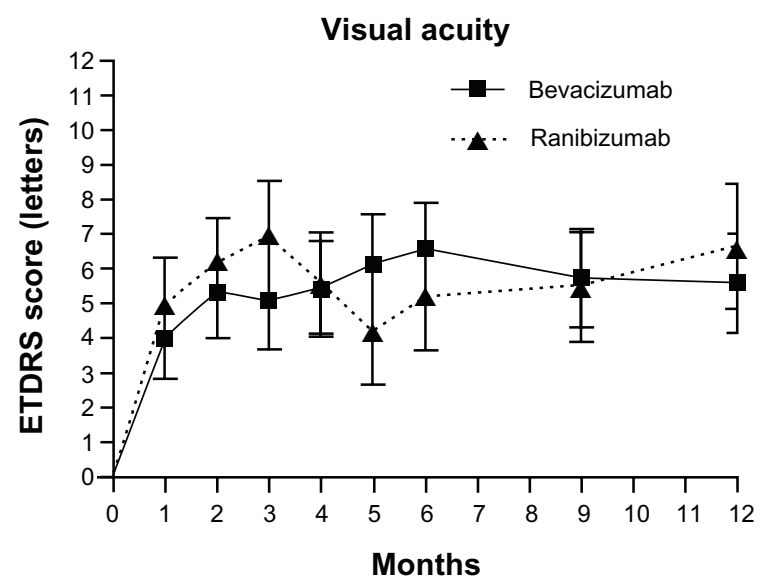

Figure I Twelve-month variation of best corrected visual acuity in patients treated for wet age-related macular degeneration either with bevacizumab or ranibizumab. Abbreviation: ETDRS, Early Treatment Diabetic Retinopathy Study. 


\section{Foveal thickness (OCT)}

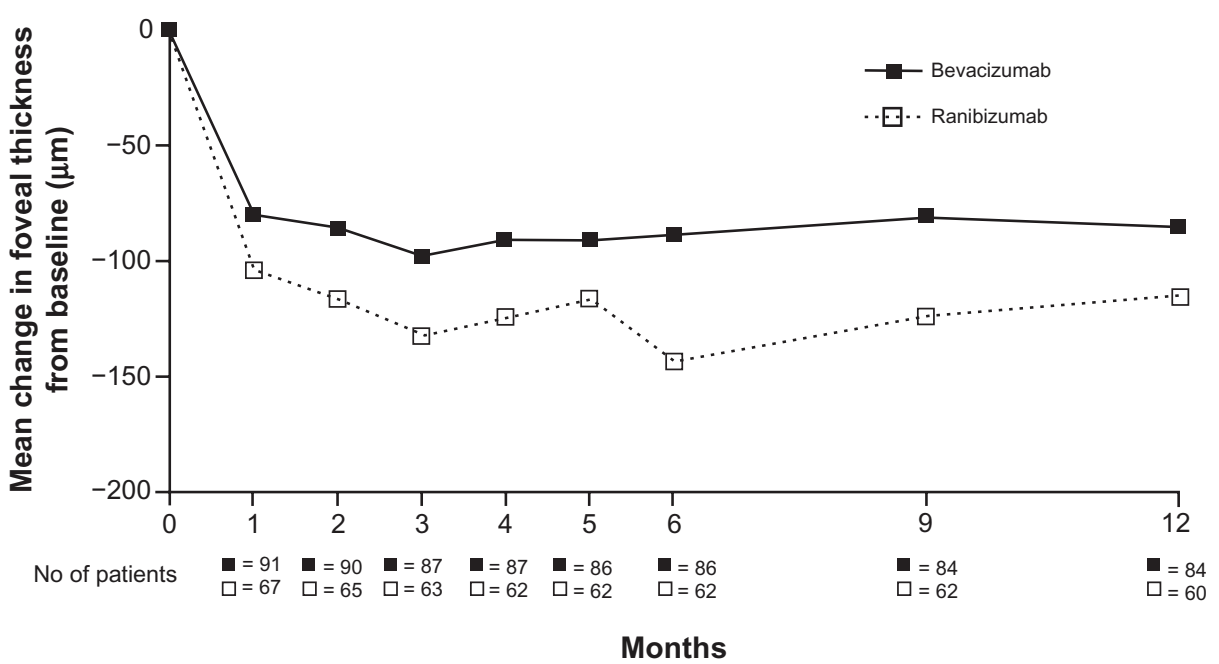

Figure 2 Twelve-month variation in central foveal thickness using OCT in patients treated for wet age-related macular degeneration either with bevacizumab or ranibizumab. Abbreviation: OCT, ocular coherence tomography.

$85.26 \mu \mathrm{m}(P<0.001 \mathrm{vs}$ baseline $)$ in the bevacizumab group $(\mathrm{n}=64)$. This difference between groups was not significant $(P=0.19)$. Mean final foveal thickness was $206.58 \mu \mathrm{m}$ for patients treated with ranibizumab and $196.69 \mu \mathrm{m}$ for those that received bevacizumab $(P=0.534)$. Variations in foveal thickness compared to baseline for each group are presented in Figures 2 and 3 and Table 3.

The mean number of treatments performed per eye during the 12 months of follow-up was $5.97( \pm 2.1)$ for the ranibizumab group $(\mathrm{n}=60)$ and $5.92( \pm 2.4)$ for the bevacizumab group $(\mathrm{n}=85)$. This difference was not statistically different $(P=0.90)$.

The number of initial injections required to obtain a dry macula was variable. Three patients in the ranibizumab

\section{Central retinal thickness (OCT)}

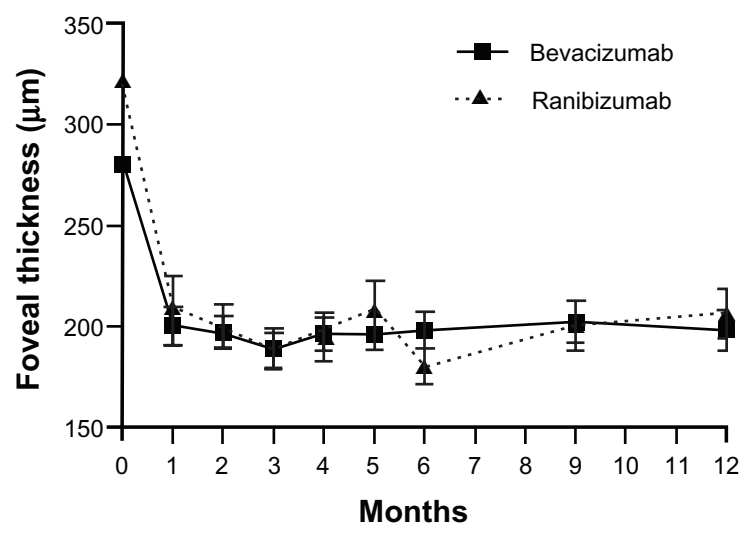

Figure 3 Central foveal thickness measured using OCT throughout 12 months of treatment with either bevacizumab or ranibizumab. Abbreviation: OCT, ocular coherence tomography. group and six patients in the bevacizumab group did not meet retreatment criteria one month after the first injection. During the following 11 months, only one patient (from the bevacizumab group) did not require further treatment. In $25.0 \%$ and $25.9 \%$ of the eyes in the ranibizumab and bevacizumab groups, respectively, a dry macula status was achieved without three initial consecutive injections (Table 4). No patients in either groups required monthly treatments during follow-up.

One patient in the bevacizumab group experienced vitreous hemorrhage and two patients in the ranibizumab group developed retinal pigment epithelium rips. There were no other significant ocular (endophthalmitis, retinal detachment, or cataract) side effects during the study.

In the bevacizumab group, one patient experienced a myocardial infarction while under treatment $(9$ months after the third initial monthly injection and did not require retreatment). One patient developed unstable angina pectoris but decided to continue treatment; she had no further complications during follow-up. Another patient was lost during follow-up following a stroke sustained 7 days after a bevacizumab injection (day 133 of follow-up; after three treatments). One lethal stroke was reported in the bevacizumab group after 8 months of follow-up and four initial monthly treatments. No systemic side effects were reported in the ranibizumab group.

\section{Discussion}

In this non-randomized, single-center, retrospective analysis, bevacizumab and ranibizumab achieved similar effects for the 
Table 3 Outcome measures at month 12

\begin{tabular}{|c|c|c|c|}
\hline & $\begin{array}{l}\text { Ranibizumab } \\
(n=60)\end{array}$ & $\begin{array}{l}\text { Bevacizumab } \\
(n=85)\end{array}$ & $P$ \\
\hline \multicolumn{4}{|c|}{ Change from baseline BCVA score } \\
\hline Mean no of letters & $6.65( \pm \mid 3.9)$ & $5.59( \pm \mid 3.2)$ & $0.64^{a}$ \\
\hline Increase of $\geq 15$ letters (\%) & $15(25.0)$ & $21(24.7)$ & $0.97^{\mathrm{b}}$ \\
\hline Increase of $>0$ letters (\%) & $42(70.0)$ & $56(65.9)$ & $0.60^{b}$ \\
\hline Decrease of $\geq 15$ letters (\%) & $3(5.0)$ & $7(8.2)$ & $0.45^{\mathrm{b}}$ \\
\hline \multicolumn{4}{|l|}{ Foveal thickness $(\mu \mathrm{m})$} \\
\hline Mean $( \pm S D)$ & $206.6( \pm 94.7)$ & $196.7( \pm 93.3)$ & $0.53^{\mathrm{a}}$ \\
\hline Mean change from baseline $( \pm S D)$ & $-115.1( \pm 120.9)$ & $-85.3( \pm 143.2)$ & $0.19^{\mathrm{a}}$ \\
\hline Mean no of treatments $( \pm S D)$ & $5.97( \pm 2.15)$ & $5.92( \pm 2.36)$ & $0.90^{\mathrm{a}}$ \\
\hline
\end{tabular}

Notes: aPearson chi-square; bindependent sample $t$-test; conly 84 patients treated with bevacizumab had OCT data available at month 12.

Abbreviations: BCVA, best corrected visual acuity in Early Treatment Diabetic Retinopathy Study scores; RAP, retinal angiomatous proliferation.

control of wet AMD using a 1+PRN regimen of treatment. The mean gain in BCVA at 12 months was approximately six ETDRS letters in both groups with a mean number of nearly six injections.

Until recently, ranibizumab was the only drug that had been shown to improve mean BCVA in patients with wet AMD in large, double-blinded, multicentric randomized clinical trials. ${ }^{10,12,16-18}$ Bevacizumab showed promising results in the CATT trial, ${ }^{13} \mathrm{ABC}$ trial, ${ }^{36}$ and in published series $^{8,11,28,29,37-39}$ and is significantly cheaper than ranibizumab, allowing treatments of a greater number of patients. However, its intravitreal efficacy and safety are primary concerns for many ophthalmologists. Larger, randomized, prospective clinical trials comparing the two anti-VEGF molecules are in progress in different countries, but the results are not yet available.

In most reports describing the efficacy and safety of bevacizumab and ranibizumab, the drugs were investigated separately. The only direct comparison between the two

Table 4 Number of initial consecutive injections to achieve a dry macula

\begin{tabular}{lll}
\hline & $\begin{array}{l}\text { Ranibizumab } \\
\mathbf{n}(\%)\end{array}$ & $\begin{array}{l}\text { Bevacizumab } \\
\mathbf{n}(\%)\end{array}$ \\
\hline $\mathrm{I} \mathrm{inj}$ & $3(5.0)$ & $6(7.1)$ \\
$2 \mathrm{inj}$ & $12(20.0)$ & $16(18.8)$ \\
$3 \mathrm{inj}$ & $10(16.7)$ & $26(30.6)$ \\
$4 \mathrm{inj}$ & $10(16.7)$ & $11(12.9)$ \\
$5 \mathrm{inj}$ & $13(21.7)$ & $8(9.4)$ \\
$6 \mathrm{inj}$ & $6(10.0)$ & $6(7.1)$ \\
$7 \mathrm{inj}$ & $0(0)$ & $4(4.7)$ \\
$8 \mathrm{inj}$ & $2(3.3)$ & $1(1.2)$ \\
$9 \mathrm{inj}$ & $2(3.3)$ & $5(5.9)$ \\
$10 \mathrm{inj}$ & $2(3.3)$ & $2(2.4)$ \\
Mean $^{\mathrm{a}}$ & $4.20 \mathrm{inj}$ & $3.96 \mathrm{inj}$ \\
\hline
\end{tabular}

Notes: a ${ }^{D}$ ifference between the mean number initial consecutive injections performed per eye in each group was not statistically significant $(P=0.53$; independent samples $t$-test). molecules was performed in the CATT, which included four cohorts for comparing bevacizumab and ranibizumab in monthly or as-needed regimens of treatment. The results showed that ranibizumab given as-needed was equivalent to ranibizumab given monthly, with a mean difference of 1.7 letters. Bevacizumab given as-needed was equivalent to bevacizumab monthly over 36 weeks, but at 52 weeks the difference of 2.1 letters yielded an inconclusive comparison. ${ }^{13}$

Although our study was conducted in a clinical setting with no restrictions regarding BCVA at baseline or percentage of hemorrhage, atrophy or fibrosis in the CNV lesions, retreatment, and follow-up criteria were very similar to the CATT. In our series, initial vision was lower than in the CATT; however, our results are comparable to those of the as-needed cohorts of ranibizumab and bevacizumab in the CATT. At 12 months, the bevacizumab PRN group in the CATT improved by 5.9 letters, which is similar to our results (+5.59). The same is true for ranibizumab (6.8 letter gain in the CATT and 6.65 letter gain in our cohort). Mean visual gains were very similar despite differences in mean BCVA at baseline, which were lower in our patients (mean of 41 letters in our study vs mean of 60 letters in CATT). This shows that patients with low vision may also benefit from anti-VEGF therapy. The percentage of patients with moderate visual loss and significant visual gain were also very similar between the studies. The mean number of treatments performed was lower in our study compared to that in the CATT, but the visual results are nearly identical. Using the $1+$ PRN strategy of treatment, based on OCT and clinical data, we achieved a statistically significant and sustained visual gain over 12 months, with a mean of 5.97 injections in the ranibizumab group and 5.88 injections in the bevacizumab group. The number of injections was less than the number of injections in the CATT, which may be related to small differences in retreatment criteria. In the CATT, retreatment 
criteria included fluid on the OCT, new or persistent hemorrhage, decreased visual acuity as compared to the previous examination, or dye leakage or increased lesion size in FA. The lower threshold to fluid decided by trial investigators and wider retreatment criteria used in CATT likely led to a higher number of injections. In our series, $24.7 \%$ of eyes obtained significant visual gain, and less than $5 \%$ of patients had a maximum of 10 injections during the 12 months.

Apart from the CATT, only a few studies have compared bevacizumab to ranibizumab using the same treatment and retreatment protocols for both drugs. ${ }^{33-35}$ In the present study, bevacizumab showed similar results to ranibizumab as both drugs significantly improved mean BCVA and reduced foveal thickness. An expected, a statistically significant increase in BCVA and decrease in mean foveal thickness occurred in both groups after the first injection. Importantly, these changes, which were similar between the two cohorts, agreed with the results of previous studies ${ }^{18}$ and were maintained throughout the follow-up period.

Only one eye per patient was included in the study in order to eliminate bias that may have been introduced by using two eyes from the same patient. Including two eyes per patient may lead to a standard deviation with smaller amplitudes, resulting in biased statistically significant differences. ${ }^{40-42}$

The strategy of treatment was $1+P R N$. The data suggest that there is no benefit to using a three-injection loading dose rather than a $1+\mathrm{PRN}$ regimen of treatment. This is similar to the results of the CATT. In our series, at least $25 \%$ of patients in each group did not require three initial consecutive injections as proposed by the European label of Lucentis ${ }^{\circledR}$. Loading dose benefits are emphasized by many authors but have not been demonstrated in clinical trial settings and are label-recommended based only on statistical analysis, which may lead to overtreatment. ${ }^{43}$

The increase in vision observed in the ranibizumab group was less than those observed in the ANCHOR, MARINA, and PrONTO trials, but higher than those observed in the PIER and SAILOR trials for the same time point. ${ }^{10,12,16,17,20,21,44,45}$ Our results using a $1+\mathrm{PRN}$ regimen are comparable to those of SUSTAIN trial. ${ }^{18}$ Our retreatment criteria are more extensive than those used in the SUSTAIN trial; additionally, without an initial loading dose, the 12 -month results are very similar. In both groups, a significant decrease in central foveal thickness was observed over the 12-month study period. Although the two groups differed in mean central foveal thickness at baseline, this difference was not statistically significant. However, the relationship between initial foveal thickness and response to treatment is not completely understood. It is presently not clear whether greater baseline foveal thickness leads to a greater improvement in visual acuity with any anti-VEGF treatment. However, mean central foveal thickness values were very similar immediately after the first injection and remained relatively stable during the 6 months of follow-up.

Non-statistically significant differences in efficacy observed in our study are in agreement with data from the CATT $;{ }^{13}$ both drugs are equally effective for treating wet AMD. This highlights very important economic issues. The disparity of prices between the two drugs is as important as the clinical findings, particularly regarding the connection between visual results and patient quality of life. However, systemic safety must be fully evaluated to understand the role of bevacizumab in the treatment of wet AMD.

There are several limitations to our study. This study was a retrospective, uncontrolled, non-randomized, and singlecenter study, which is insufficiently powered to identify differences in drug-related adverse events. The low number of patients and short follow-up time limit our ability to draw conclusions regarding safety. A small number of patients were treated and lost to follow-up for unknown reasons. Thus, we cannot speculate regarding the apparent higher rate of adverse events in the bevacizumab group.

Results from CATT, a large, multicentric, randomized prospective clinical trial, revealed no differences in treating wet AMD with either ranibizumab or bevacizumab using a $1+$ PRN strategy. Importantly, these results were found in a clinical setting. Thus, patients can be treated in regular clinical practice with either drug using this regime. However, large multicentric data are needed to make conclusions regarding systemic safety, which is an important factor in determining treatment.

\section{Acknowledgments}

We thank the technicians Hugo Monteiro, Paulo Rocha, and Fátima Matos for their dedication and work.

\section{Disclosure}

Ângela M Carneiro has participated in advisory boards for Novartis Pharma and Bayer.

Financial Support: grants from: "Sociedade Portuguesa de Oftalmologia" and "Hospital de São João".

\section{References}

1. Bressler NM, Bressler SB, Congdon NG, et al. Potential public health impact of Age-Related Eye Disease Study results: AREDS report no 11. Arch Ophthalmol. 2003;121(11):1621-1624.

2. Klein R, Peto T, Bird A, Vannewkirk MR. The epidemiology of age-related macular degeneration. Am J Ophthalmol. Mar 2004;137(3):486-495. 
3. Congdon N, O'Colmain B, Klaver CC, et al. Causes and prevalence of visual impairment among adults in the United States. Arch Ophthalmol. 2004;122(4):477-485.

4. Friedman DS, O'Colmain BJ, Munoz B, et al. Prevalence of age-related macular degeneration in the United States. Arch Ophthalmol. 2004; 122(4):564-572.

5. Vingerling JR, Dielemans I, Hofman A, et al. The prevalence of agerelated maculopathy in the Rotterdam Study. Ophthalmology. 1995; 102(2):205-210.

6. Kahn HA, Leibowitz HM, Ganley JP, et al. The Framingham Eye Study. I. Outline and major prevalence findings. Am J Epidemiol. 1977; 106(1):17-32.

7. Foran S, Wang JJ, Mitchell P. Causes of visual impairment in two older population cross-sections: the Blue Mountains Eye Study. Ophthalmic Epidemiol. 2003;10(4):215-225.

8. Spaide RF, Laud K, Fine HF, et al. Intravitreal bevacizumab treatment of choroidal neovascularization secondary to age-related macular degeneration. Retina. 2006;26(4):383-390.

9. Rosenfeld PJ, Moshfeghi AA, Puliafito CA. Optical coherence tomography findings after an intravitreal injection of bevacizumab (avastin) for neovascular age-related macular degeneration. Ophthalmic Surg Lasers Imaging. 2005;36(4):331-335.

10. Rosenfeld PJ, Brown DM, Heier JS, et al. Ranibizumab for neovascular age-related macular degeneration. $N$ Engl J Med. 5, 2006;355(14): 1419-1431.

11. Bashshur ZF, Haddad ZA, Schakal A, Jaafar RF, Saab M, Noureddin BN. Intravitreal bevacizumab for treatment of neovascular age-related macular degeneration: a one-year prospective study. Am J Ophthalmol. 2008;145(2):249-256.

12. Brown DM, Michels M, Kaiser PK, Heier JS, Sy JP, Ianchulev T. Ranibizumab versus verteporfin photodynamic therapy for neovascular age-related macular degeneration: Two-year results of the ANCHOR study. Ophthalmology. 2009;116(1):57-65 e55.

13. Martin DF, Maguire MG, Ying GS, Grunwald JE, Fine SL, Jaffe GJ. Ranibizumab and bevacizumab for neovascular age-related macular degeneration. N Engl J Med. 2011;364(20):1897-1908.

14. Ferrara N, Damico L, Shams N, Lowman H, Kim R. Development of ranibizumab, an anti-vascular endothelial growth factor antigen binding fragment, as therapy for neovascular age-related macular degeneration. Retina. 2006;26(8):859-870.

15. Mordenti J, Cuthbertson RA, Ferrara N, et al. Comparisons of the intraocular tissue distribution, pharmacokinetics, and safety of 125Ilabeled full-length and Fab antibodies in rhesus monkeys following intravitreal administration. Toxicol Pathol. 1999;27(5):536-544.

16. Brown DM, Kaiser PK, Michels M, et al. Ranibizumab versus verteporfin for neovascular age-related macular degeneration. $N$ Engl J Med. 2006;355(14):1432-1444.

17. Kaiser PK, Blodi BA, Shapiro H, Acharya NR. Angiographic and optical coherence tomographic results of the MARINA study of ranibizumab in neovascular age-related macular degeneration. Ophthalmology. 2007;114(10): 1868-1875.

18. Mitchell P, Korobelnik JF, Lanzetta P, et al. Ranibizumab (Lucentis) in neovascular age-related macular degeneration: evidence from clinical trials. Br J Ophthalmol. 2010;94(1):2-13.

19. Heier JS, Antoszyk AN, Pavan PR, et al. Ranibizumab for treatment of neovascular age-related macular degeneration: a phase I/II multicenter, controlled, multidose study. Ophthalmology. 2006;113(4): 633. e1-e4.

20. Regillo CD, Brown DM, Abraham P, et al. Randomized, doublemasked, sham-controlled trial of ranibizumab for neovascular agerelated macular degeneration: PIER Study year 1. Am J Ophthalmol. 2008;145(2):239-248.

21. Boyer DS, Heier JS, Brown DM, Francom SF, Ianchulev T, Rubio RG. A Phase IIIb study to evaluate the safety of ranibizumab in subjects with neovascular age-related macular degeneration. Ophthalmology. 2009;116(9):1731-1739.
22. Holz FG, Korobelnik JF, Lanzetta P, et al. The effects of a flexible visual acuity-driven ranibizumab treatment regimen in age-related macular degeneration: outcomes of a drug and disease model. Invest Ophthalmol Vis Sci. 2010;51(1):405-412.

23. Brown DM, Regillo CD. Anti-VEGF agents in the treatment of neovascular age-related macular degeneration: applying clinical trial results to the treatment of everyday patients. Am J Ophthalmol. 2007; 144(4):627-637.

24. Atmani K, Voigt M, Le Tien V, et al. Ranibizumab for retinal angiomatous proliferation in age-related macular degeneration. Eye (Lond). 2010;24(7):1193-1198.

25. Mendrinos E, Mangioris G, Papadopoulou D, Donati G, Pournaras C. One year results of the effect of intravitreal ranibizumab on the retinal arteriolar diameter in patients with neovascular age-related macular degeneration. Invest Ophthalmol Vis Sci. 2009.

26. Hurwitz H, Fehrenbacher L, Novotny W, et al. Bevacizumab plus irinotecan, fluorouracil, and leucovorin for metastatic colorectal cancer. N Engl J Med. 2004;350(23):2335-2342.

27. Ferrara N, Kerbel RS. Angiogenesis as a therapeutic target. Nature. 2005;438(7070):967-974

28. Sacu S, Michels S, Prager F, et al. Randomised clinical trial of intravitreal Avastin vs photodynamic therapy and intravitreal triamcinolone: long-term results. Eye. 2009;23(12):2223-2227.

29. Rich RM, Rosenfeld PJ, Puliafito CA, et al. Short-term safety and efficacy of intravitreal bevacizumab (Avastin) for neovascular agerelated macular degeneration. Retina. 2006;26(5):495-511.

30. Conrad PW, Zacks DN, Johnson MW. Intravitreal bevacizumab has initial clinical benefit lasting eight weeks in eyes with neovascular age-related macular degeneration. Clin Ophthalmol. 2008;2(4): 727-733.

31. Leydolt C, Michels S, Prager F, et al. Effect of intravitreal bevacizumab $(\operatorname{Avastin}(\mathrm{R}))$ in neovascular age-related macular degeneration using a treatment regimen based on optical coherence tomography: 6- and 12-month results. Acta Ophthalmol. 2010;88(5):594-600.

32. Subramanian ML, Ness S, Abedi G, et al. Bevacizumab vs ranibizumab for age-related macular degeneration: early results of a prospective double-masked, randomized clinical trial. Am J Ophthalmol. 2009; 148(6):875-882. e1

33. Stepien KE, Rosenfeld PJ, Puliafito CA, et al. Comparison of intravitreal bevacizumab followed by ranibizumab for the treatment of neovascular age-related macular degeneration. Retina. 2009;29(8):1067-1073.

34. Landa G, Amde W, Doshi V, et al. Comparative study of intravitreal bevacizumab (avastin) versus ranibizumab (lucentis) in the treatment of neovascular age-related macular degeneration. Ophthalmologica. 2009;223(6):370-375.

35. Gamulescu MA, Radeck V, Lustinger B, Fink B, Helbig H. Bevacizumab versus ranibizumab in the treatment of exudative age-related macular degeneration. Int Ophthalmol. 2010;30(3):261-266.

36. Tufail A, Patel PJ, Egan C, et al. Bevacizumab for neovascular age related macular degeneration (ABC Trial): multicentre randomised double masked study. BMJ. 2010;340:c2459.

37. Bashshur ZF, Schakal A, Hamam RN, El Haibi CP, Jaafar RF, Noureddin BN. Intravitreal bevacizumab vs verteporfin photodynamic therapy for neovascular age-related macular degeneration. Arch Ophthalmol. 2007;125(10):1357-1361.

38. Ghazi NG, Knape RM, Kirk TQ, Tiedeman JS, Conway BP. Intravitreal bevacizumab (avastin) treatment of retinal angiomatous proliferation. Retina. 2008;28(5):689-695.

39. Goff MJ, Johnson RN, McDonald HR, Ai E, Jumper JM, Fu A. Intravitreal bevacizumab for previously treated choroidal neovascularization from age-related macular degeneration. Retina. 2007;27(4):432-438.

40. Glynn RJ, Rosner B. Accounting for the correlation between fellow eyes in regression analysis. Arch Ophthalmol. 1992;110(3):381-387.

41. Katz J, Zeger S, Liang KY. Appropriate statistical methods to account for similarities in binary outcomes between fellow eyes. Invest Ophthalmol Vis Sci. 1994;35(5):2461-2465. 
42. Murdoch IE, Morris SS, Cousens SN. People and eyes: statistical approaches in ophthalmology. Br J Ophthalmol. 1998;82(8): 971-973.

43. Holz FG, Korobelnik JF, Lanzetta P, et al. The effects of a flexible visual acuity-driven ranibizumab treatment regimen in age-related macular degeneration: outcomes of a drug and disease model. Invest Ophthalmol Vis Sci. 2010;51(1):405-412.

44. Fung AE, Lalwani GA, Rosenfeld PJ, et al. An optical coherence tomography-guided, variable dosing regimen with intravitreal ranibizumab (Lucentis) for neovascular age-related macular degeneration. Am J Ophthalmol. 2007;143(4):566-583.
45. Lalwani GA, Rosenfeld PJ, Fung AE, et al. A variable-dosing regimen with intravitreal ranibizumab for neovascular age-related macular degeneration: year 2 of the PrONTO Study. Am J Ophthalmol. 2009; 148(1):43. e1-58. e1.

\section{Publish your work in this journal}

Clinical Ophthalmology is an international, peer-reviewed journal covering all subspecialties within ophthalmology. Key topics include: Optometry; Visual science; Pharmacology and drug therapy in eye diseases; Basic Sciences; Primary and Secondary eye care; Patien Safety and Quality of Care Improvements. This journal is indexed on

Submit your manuscript here: http://www.dovepress.com/clinical-ophthalmology-journal

\section{Dovepress}

PubMed Central and CAS, and is the official journal of The Society of Clinical Ophthalmology (SCO). The manuscript management system is completely online and includes a very quick and fair peer-review system, which is all easy to use. Visit http://www.dovepress.com/ testimonials.php to read real quotes from published authors. 